\title{
High-Throughput Screening Single-Atom Alloy for Electroreduction of Dinitrogen to Ammonias
}

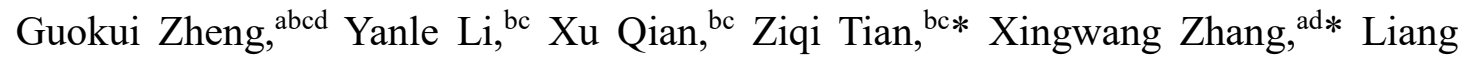
Chen ${ }^{\text {bc* }}$

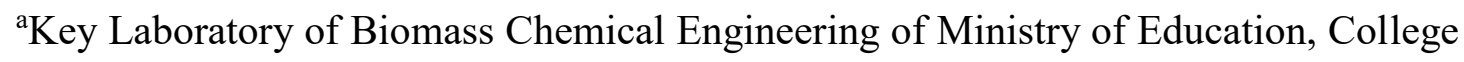
of Chemical and Biological Engineering Zhejiang University, Zheda Road 38, Hangzhou, Zhejiang Province 310027, China.

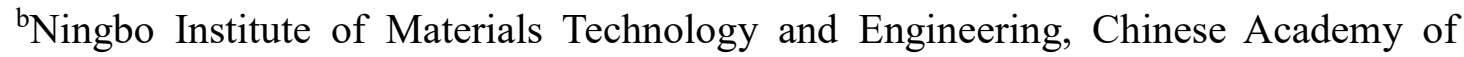
Sciences, Ningbo 315201, Zhejiang, China.

${ }^{c}$ University of Chinese Academy of Sciences, 100049, Beijing, China.

${ }^{\mathrm{d}}$ Institute of Zhejiang University-Quzhou, Quzhou 324000, China

Email: tianziqi@nimte.ac.cn; xwzhang@zju.edu.cn; chenliang@nimte.ac.cn

\begin{abstract}
Exploring electrocatalyst with high activity, selectivity and stability is essential for development of applicable electrocatalytic ammonia synthesis technology. By performing density functional theory calculations, we systematically investigated a series of transition-metal doped Au-based single atom alloys (SAAs) as promising electrocatalysts for nitrogen reduction reaction (NRR). For Au-based electrocatalyst, the first hydrogenation step $\left({ }^{*} \mathrm{~N}_{2} \rightarrow * \mathrm{NNH}\right)$ normally determines the limiting potential of the overall reaction process. Compared with pristine $\mathrm{Au}(111)$ surface, introducing single atom can significantly enhance the binding strength of $\mathrm{N}_{2}$, leading to decreased energy barrier of the key step, i.e., $\Delta \mathrm{G}\left({ }^{*} \mathrm{~N}_{2} \rightarrow * \mathrm{NNH}\right)$. According to simulation results, three descriptors were proposed to describe $\Delta \mathrm{G}\left({ }^{*} \mathrm{~N}_{2} \rightarrow{ }^{*} \mathrm{NNH}\right)$, including $\Delta \mathrm{G}\left({ }^{*} \mathrm{NNH}\right)$, $d$-band center, and $\frac{\mathrm{d}}{\sqrt{\mathrm{E}_{\mathrm{m}}}}$. Eight doped elements (Ti, V, Nb, Ru, Ta, Os, W, and Mo) were initially screened out with limiting potential ranging from $-0.75 \mathrm{~V}$ to $-0.30 \mathrm{~V}$. Particularly, Mo- and W-doped systems possess the best activity with limiting potentials
\end{abstract}


of $-0.30 \mathrm{~V}$, respectively. Then the intrinsic relationship between structure and the potential performance was further analyzed by using machine-learning. The selectivity, feasibility, stability of these candidates were also evaluated, confirming that SAA containing $\mathrm{Mo}, \mathrm{Ru}$, Ta, and $\mathrm{W}$ could be outstanding NRR electrocatalysts. This work not only broadens the understating of SAA application in electrocatalysis, but also devotes to the discovery of novel NRR electrocatalysts.

KEYWORDS: Single-atom alloy, Nitrogen reduction reaction, Electrocatalysis, High-throughput calculations, Machine-learning

\section{Introduction}

Ammonia $\left(\mathrm{NH}_{3}\right)$ is one of the world's most synthesized chemicals, which is the key building block for fertilizer currently and an ideal carrier for renewable energy in future. ${ }^{12,3}$ To date, synthesis of ammonia highly relies on the Haber-Bosch process that occurs at high temperatures and high pressures in the presence of iron-based catalysts. ${ }^{4,5}$ Electrochemical nitrogen reduction reaction (NRR) at ambient conditions is an attractive alternative to the Haber-Bosch process. Developing active, selective, and stable electrocatalysts is still challenged. ${ }^{6}$ The competition to hydrogenation evolution reaction (HER) significantly limits the efficiency of NRR process. Because of the inertness to HER and high stability, several noble metals have been reported as promising electrocatalysts, such as $\mathrm{Au}, \mathrm{Pt}$, and $\mathrm{Ru} .{ }^{7-10}$ Among them, Au exhibits the most efficient performance owing to the low activity of competitive HER. ${ }^{11,12}$ Previous studies demonstrated that the lack of empty $d$-orbits to accept lone-pair electrons from $\mathrm{N}_{2}$ may result in extremely weak adsorption to $\mathrm{N}_{2}$, and herein difficulty in breaking triple N-N bond. ${ }^{13,14}$ The potential determining step (PDS) is normally the first hydrogenation step from ${ }^{*} \mathrm{~N}_{2}$ to $* \mathrm{NNH}$ with potential barrier over $2.0 \mathrm{eV} .{ }^{15,16}$ Can we improve the activity of Au-based materials through a simple strategy?

Since single-atom catalyst (SAC) was first proposed by Zhang et al, ${ }^{17} \mathrm{SACs}$ have been emerging in various reactions, such as traditional catalysis, photocatalysis, and 
electrocatalysis. ${ }^{18-20}$ SACs can be constructed based on a variety of substrates, such as transition metal oxides ${ }^{21-26}$ carbon-based materials, ${ }^{27,28}$ transition metal chalcogenide $^{29-}$ 31, and MXenes. ${ }^{32,33}$ Particularly, when the substrate is metal, the SAC is also called as single-atom alloy (SAA). ${ }^{34}$ Numerous SAA catalytic systems have been reported for their well-defined active site and excellent catalytic performance. ${ }^{34-36}$ For example, $\mathrm{CuPd}$ SAA shows high selective for the photocatalytic conversion of $\mathrm{CO}_{2}$ to $\mathrm{CH}_{4}$. The $d$-band center of isolated $\mathrm{Cu}$ was raised in $\mathrm{Pd}$ substrate, leading to enhanced binding with key intermediate. ${ }^{37}$ On the other hand, $\mathrm{PdCu}$ SAA enhances the selectivity toward alcohols for electrochemical $\mathrm{CO}_{2}$ reduction, compared to common $\mathrm{Cu}$-based catalysts. ${ }^{38}$ Hydrogen oxidation reaction (HOR) activity can be regulated by isolating single $\mathrm{Ni}$ atom into $\mathrm{Ru}$ nanosheet. ${ }^{39}$ Inspired by these works, we proposed a singleatom alloying strategy to improve the performance of Au-based materials for NNR.

To validate our hypothesis, the NRR performance of a series of $\mathrm{M} / \mathrm{Au}(111)$ systems $(\mathrm{M}=3 d, 4 d$, and $5 d$ transition metals) were investigated by using density functional theory (DFT) calculation. $\mathrm{Au}(111)$ is the most stable facet that has been widely studied. ${ }^{40-42}$ Our theoretical results indicate that many SAAs can enhance the binding strength of $\mathrm{N}_{2}$ and reduce the potential barrier of the first hydrogenation step $\left(\Delta \mathrm{G}\left({ }^{*} \mathrm{~N}_{2} \rightarrow{ }^{*} \mathrm{NNH}\right)\right)$. Three descriptors were established to describe $\Delta \mathrm{G}\left({ }^{*} \mathrm{~N}_{2} \rightarrow{ }^{*} \mathrm{NNH}\right)$, i.e., $\Delta \mathrm{G}(* \mathrm{NNH}), d$-band center of the doped metal, and $\frac{\mathbf{d}}{\sqrt{\mathbf{E}_{\mathbf{m}}}}(d$ is the number of $d$ electron in valence orbital of doped metal; $E_{m}$ is the electronegativity of doped metal). $\Delta \mathrm{G}(* \mathrm{NNH})$ exhibits a linear relationship with $\Delta \mathrm{G}\left({ }^{*} \mathrm{~N}_{2} \rightarrow * \mathrm{NNH}\right)$, while the $d$-band center and $\frac{\mathbf{d}}{\sqrt{\mathbf{E}_{\mathbf{m}}}}$ show a volcano relationship. Moreover, combining with machinelearning, we unveiled the intrinsic correlations between structure and $\Delta \mathrm{G}\left({ }^{*} \mathrm{~N}_{2} \rightarrow * \mathrm{NNH}\right)$. Through the computation of whole reaction paths, eight $\mathrm{M} / \mathrm{Au}(111)$ systems $(\mathrm{M}=\mathrm{Ti}, \mathrm{V}$, $\mathrm{Nb}, \mathrm{Mo}, \mathrm{Ru}, \mathrm{Ta}, \mathrm{W}$, and Os) were suggested to possess high activity with limiting potential ranging from $-0.75 \mathrm{~V}$ to $-0.30 \mathrm{~V}$. According to $\frac{\mathbf{d}}{\sqrt{\mathbf{E}_{\mathbf{m}}}}$, we further predicted Moand W/Ag(111) SAAs could be highly active. After considering selectivity, feasibility, electrochemical and thermal stability, four $\mathrm{M} / \mathrm{Au}(111)$ candidates $(\mathrm{M}=\mathrm{Mo}, \mathrm{W}, \mathrm{Ru}$, and 
Ta) were finally screened out as excellent catalysts for NNR.

\section{Computational Details}

Spin-polarized DFT computations were employed by using Vienna Ab initio Simulation Package (VASP). ${ }^{43}$ The Perdew-Burke-Erzenhof (PBE) functional in the generalized gradient approximation (GGA) was applied to describe the exchangecorrelation energy. ${ }^{44}$ The ion-electron interaction was described by Projector Augmented Wave (PAW) with cutoff energy of $450 \mathrm{eV} .^{45}$ The convergence criteria for energy and force were set to be $10^{-5} \mathrm{eV}$ and $0.03 \mathrm{eV} / \AA \AA$, respectively. The van der Waals interaction was considered by the empirical correction of the Grimme's scheme (DFTD2). ${ }^{46}$ The $4 \times 4 \times 1$ supercell of $\mathrm{Au}(111)$ facet with four layers was taken as the substrate model. To reproduce the bulk properties, two bottom layers were fixed. The Brillouin zone was sampled by Gamma centered $3 \times 3 \times 1$ Monkhorst-Pack grid for structural optimizations. ${ }^{47}$ The density of states was calculated by using a $5 \times 5 \times 1$ Monkhorst-Pack grid. The $d$-band center was computed by VASPKIT code. ${ }^{48}$ The figure of the model structures were generated by using ASE. ${ }^{49}$

The NRR process was studied based on the computational hydrogen evolution model (CHE).$^{50}$ The Gibbs free energy change $(\Delta \mathrm{G})$ was calculated by the following equation:

$$
\triangle G=\triangle E_{\mathrm{DFT}}+\triangle E_{\mathrm{zpe}}-T \triangle S
$$

where $\Delta E_{\mathrm{DFT}}$ is the total energy difference obtained from DFT calculation; $\Delta E_{\text {zpe }}$ and $\Delta S$ are zero-point correction and the variation of entropy computed from vibrational analysis by VASPKIT code. ${ }^{48} T$ is temperature $(298.15 \mathrm{~K}$ in this work). The implicit solvation model, VASPsol, was used to consider the effect of $\mathrm{H}_{2} \mathrm{O}$ solvation. The dielectric constant was $78.4 .{ }^{51}$ To evaluate the activity of NRR, the limiting potential $\left(\mathrm{U}_{\mathrm{L}}\right)$ was calculated by

$$
U_{\mathrm{L}}=-\triangle G_{\max } / e
$$

where $\Delta \mathrm{G}_{\max }$ represents the $\Delta G$ of the PDS and $e$ is the number of transferred electron. The less negative $U_{L}$ is, the higher activity the catalyst possesses. 
The formation energy, the binding energy of single atom and the dissolution potential are further calculated to evaluate feasibility of SAA system. The formation energy was obtained by the following equation:

$$
E_{\text {form }}=E_{S A A}-E_{A u(111)}-\mu_{M}+\mu_{A u}
$$

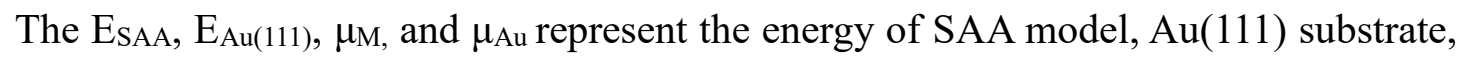
the chemical potential of the doped metal, and that of $\mathrm{Au}$, respectively. The binding energy $\left(E_{b}\right)$ was computed as:

$$
E_{b}=-\left(E_{S A A}-E_{d A u(111)}-E_{M}\right)
$$

where $E_{d A u(111)}$ and $E_{M}$ are the energies of defective $A u(111)$ with one vacancy and the energy of isolated doped metal in vacuum box, respectively. The dissolution potentials $\left(\mathrm{U}_{\text {diss }}\right)$ of SAA were from the following equations:

$$
\mathrm{U}_{\text {diss }}=\mathrm{U}_{\text {diss }}{ }^{0} \mathrm{M}-\left(\frac{E_{S A A}-E_{d A u(111)}-\mu_{M}}{n e}\right)
$$

where $\mathrm{U}_{\text {diss }}{ }^{0} \mathrm{M}$ and $n$ represent the standard dissolution potentials of doped metal $\mathrm{M}$ in the bulk phase and the number of transferred electrons, respectively. ${ }^{52}$

\section{Result and discussion}

\section{1. $\mathrm{N}_{2}$ adsorption}

Adsorption of $\mathrm{N}_{2}$ is the key step to wreck inert $\mathrm{N} \equiv \mathrm{N}$ bond. There are three possible adsorption sites around doped metal, including top, bridge, and hollow sites (Figure 1b). Different adsorption configurations are corresponding to three possible mechanisms, i.e., distal, alternating, and enzymatic pathways. ${ }^{52,53}$ We considered two typical adsorption configurations of $\mathrm{N}_{2}$ on SAAs, namely end-on and side-on (Figure 1c). Among the SAAs with $\mathrm{Au}(111)$ substrates, $\mathrm{Ag}$ - and $\mathrm{Zn}$-doped systems interact with $\mathrm{N}_{2}$ quite weakly, similar to pure $\mathrm{Au}(111)$ surface. $\mathrm{N}_{2}$ molecule lies over the doped metal, with a distance more than $3.0 \AA$, showing as physisorption. The adsorption free energies of $\mathrm{N}_{2}, \Delta \mathrm{G}\left(* \mathrm{~N}_{2}\right)$, are 0.36, 0.36, and $0.39 \mathrm{eV}$ for $\mathrm{Ag} / \mathrm{Au}(111), \mathrm{Zn} / \mathrm{Au}(111)$ and $\mathrm{Au}(111)$, respectively. In the other systems, top site on the heteroatom is preferable due to the extremely weak Au-N interaction. As shown in Table S1, the end-on configurations are more stable than side-on configurations with relatively more negative adsorption free 
energies. We focus on the discussion based on end-on configuration. The $\Delta \mathrm{G}\left({ }^{*} \mathrm{~N}_{2}\right) \mathrm{s}$ range from $0.14 \mathrm{eV}(\mathrm{Cu} / \mathrm{Au}(111))$ to $-1.14 \mathrm{eV}(\mathrm{Os} / \mathrm{Au}(111))$, indicating that most SAAs significantly enhance the $\mathrm{N}_{2}$ binding compared to pristine $\mathrm{Au}(111)$.

a

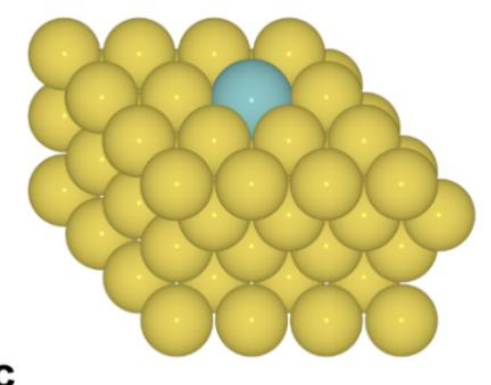

C

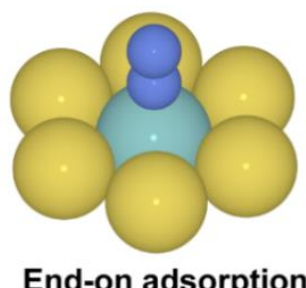

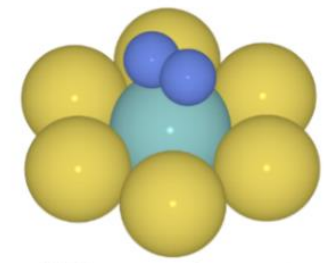

Side-on adsorption b
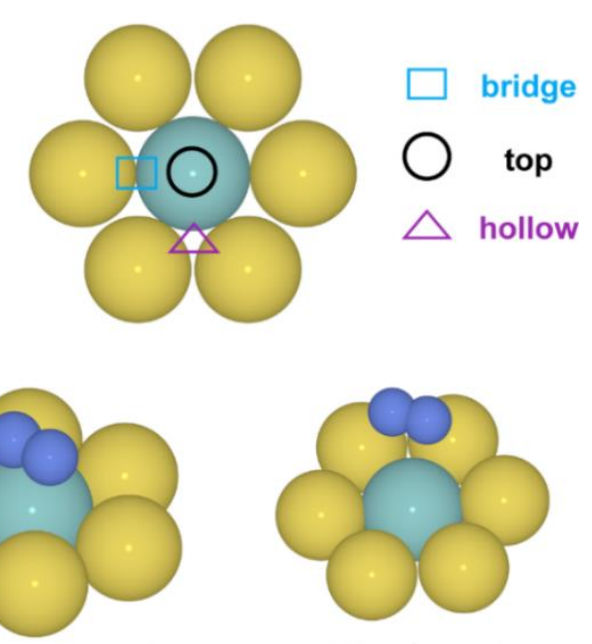

Physisorption

Figure 1.(a) The model of M/Au(111) SAA (M: doped metal); (b) The three possible adsorption sites around doped metal; (c) The two configurations of chemisorption (sideon and end-on) and physisorption configurations of $\mathrm{N}_{2}$ on SAAs.

There are two types of interactions between transition metal (TM) and adsorbed $\mathrm{N}_{2}{ }^{13,52}$ One is $\sigma$-donation that the $d$-orbital of metal accepts the lone-pair of $\mathrm{N}_{2}$. The other is $\pi$-back donation that the $d$-electrons of transition metal return back into antibonding orbitals of $\mathrm{N}_{2}$ to wreck inert $\mathrm{N} \equiv \mathrm{N}$. Taking $\mathrm{N}_{2}$ adsorbed on $\mathrm{Mo} / \mathrm{Au}(111)$ as an example, $\sigma$-donation leads to electron accumulation between Mo and $\mathrm{N}$ while $\pi$-back donation results in electron depletion of $\mathrm{N} \equiv \mathrm{N}$ bond (Figure 2a). In Figure $\mathbf{2 b}$, the project density of states (pDOS) reveals that the $\pi^{*}$ orbital of the adsorbed $\mathrm{N}_{2}$ becomes partially occupied, herein $\mathrm{N}_{2}$ bond is weakened and elongated. The $\mathrm{N}_{2}$ bond lengths in various systems are summarized in Table S2, ranging from $1.118 \AA(\mathrm{Y} / \mathrm{Au}(111))$ to $1.137 \AA(\mathrm{Os} / \mathrm{Au}(111))$ (vs. $1.115 \AA$ in the free gas molecular). In comparison, there is no apparent electron $\pi$-back donationin $\mathrm{Zn} / \mathrm{Au}(111)$ system (Figure $2 \mathbf{b}$ ), and the bond length of the adsorbed $\mathrm{N}_{2}$ is almost the same as that of $\mathrm{N}_{2}$ in gas phase. These results 
can be confirmed by the Bader analysis ${ }^{54}$ that the adsorbed $\mathrm{N}_{2}$ obtained $0.32 \mathrm{e}$ from $\mathrm{Mo} / \mathrm{Au}(111)$. Similarly, other SAAs except $\mathrm{Ag}$ - and $\mathrm{Zn} / \mathrm{Au}(111)$ also donate electron to adsorbed $\mathrm{N}_{2}$. (Table S3)
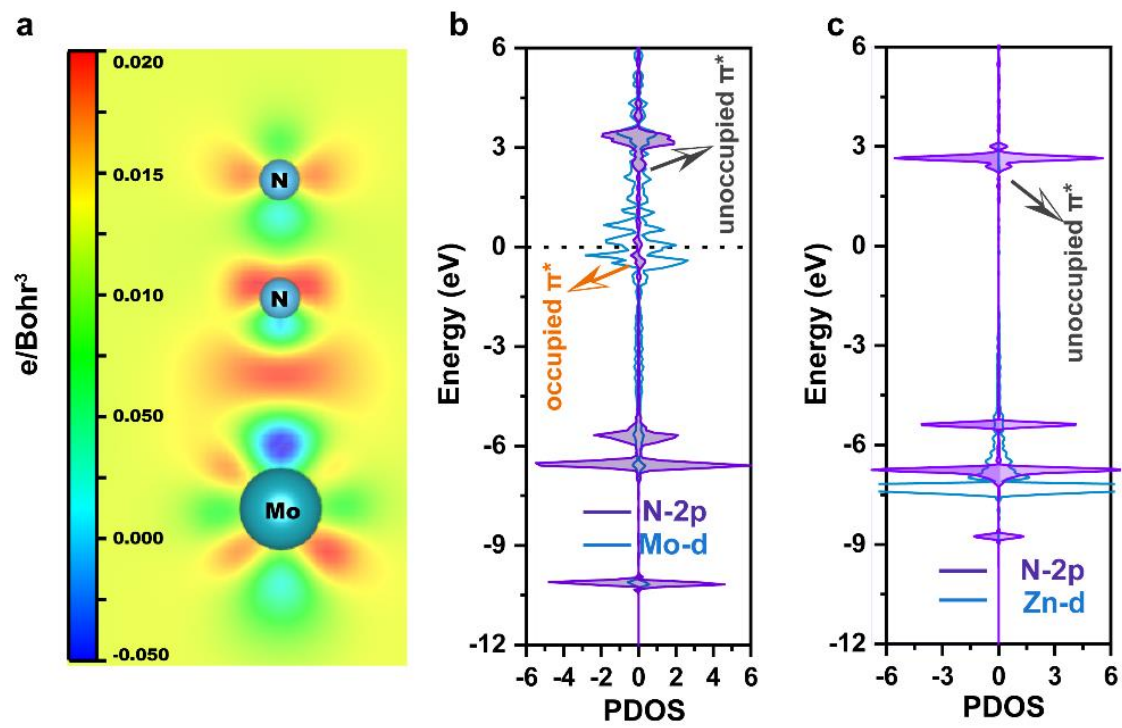

Figure 2. (a) The charge density difference of $\mathrm{N}_{2}$ adsorbed on $\mathrm{Mo} / \mathrm{Au}(111)$. The positive and negative regions represent accumulation and depletion of electron, respectively. The project density of states (pDOS) of $\mathrm{N}_{2}$ adsorbed on (b) $\mathrm{Mo} / \mathrm{Au}(111)$ and (c) $\mathrm{Zn} / \mathrm{Au}(111)$. The Fermi level is set to be zero.

\subsection{Reaction pathways of eight SAAs candidates}

The first hydrogenation step $\left({ }^{*} \mathrm{~N}_{2} \rightarrow * \mathrm{NNH}\right)$ follows $\mathrm{N}_{2}$ adsorption on the active site. As listed in Table S4, most SAAs reduce potential barriers of the first hydrogenation step $\Delta \mathrm{G}\left(* \mathrm{~N}_{2} \rightarrow * \mathrm{NNH}\right)$ compared to $\mathrm{Au}(111)$. For eight $\mathrm{M} / \mathrm{Au}(111)$ systems (Ti, V, Nb, Mo, Ru, Ta, W, and Os), $\Delta \mathrm{G}\left({ }^{*} \mathrm{~N}_{2} \rightarrow{ }^{*} \mathrm{NNH}\right)$ s decrease by more than $1.0 \mathrm{eV}$. Moreover, we established relationship between binding strengths of intermediates $\left(* \mathrm{~N}_{2}\right.$ and $\left.* \mathrm{NNH}\right)$ and $\Delta \mathrm{G}\left({ }^{*} \mathrm{~N}_{2} \rightarrow * \mathrm{NNH}\right)$. As shown in Figure 3a, $\Delta \mathrm{G}\left({ }^{*} \mathrm{~N}_{2} \rightarrow * \mathrm{NNH}\right)$ exhibits a better linear correlation with $\Delta \mathrm{G}(* \mathrm{NNH})\left(\mathrm{R}^{2}=0.92\right)$ than $\Delta \mathrm{G}\left({ }^{*} \mathrm{~N}_{2}\right)\left(\mathrm{R}^{2}=0.71\right)$, implying that the stability of $* \mathrm{NNH}$ determines $\Delta \mathrm{G}\left(* \mathrm{~N}_{2} \rightarrow * \mathrm{NNH}\right)$ (Figure 3b). ${ }^{52,55}$ 

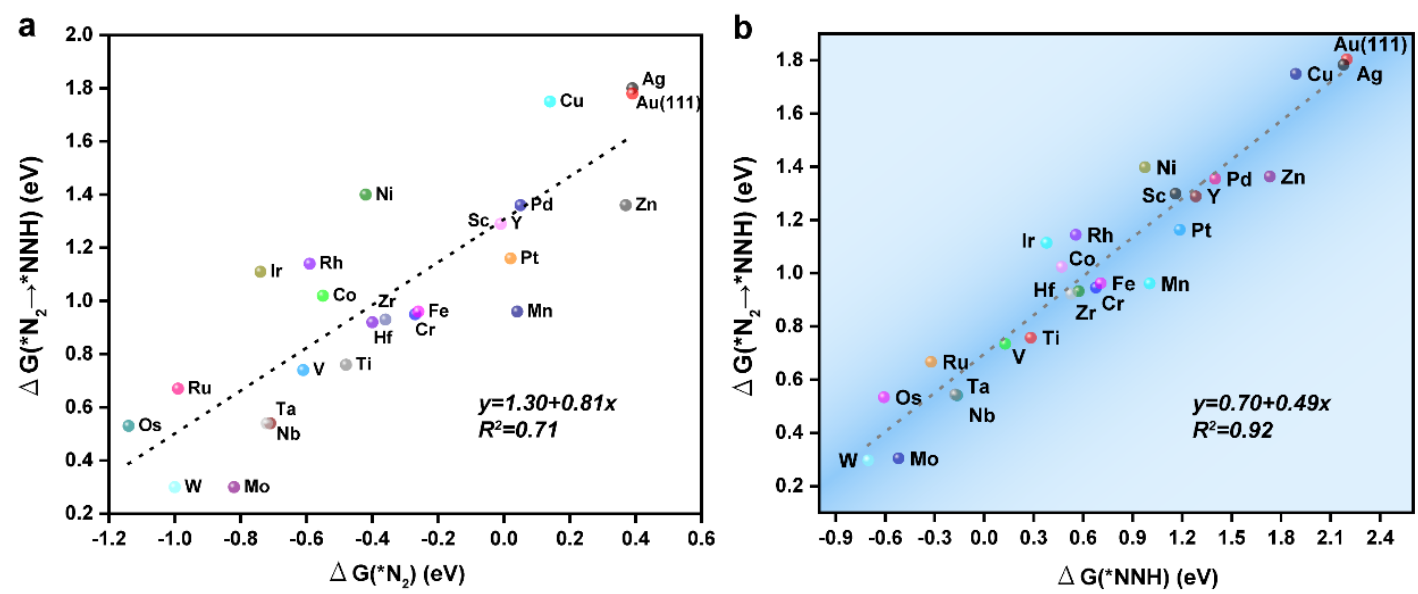

Figure 3. The relationships between $\Delta \mathrm{G}\left({ }^{*} \mathrm{~N}_{2} \rightarrow{ }^{*} \mathrm{NNH}\right)$ and the adsorption free energies of (a) $* \mathrm{~N}_{2}\left(\Delta \mathrm{G}\left(* \mathrm{~N}_{2}\right)\right)$ and (b) $* \mathrm{NNH}(\Delta \mathrm{G}(* \mathrm{NNH}))$.

According to $\Delta \mathrm{G}\left({ }^{*} \mathrm{~N}_{2} \rightarrow * \mathrm{NNH}\right)$, eight $\mathrm{M} / \mathrm{Au}(111)$ systems $(\mathrm{M}=\mathrm{Ti}, \mathrm{V}, \mathrm{Nb}, \mathrm{Mo}, \mathrm{Ru}$, Ta, W, and Os) are supposed to possess outstanding performance, with relatively small $\Delta \mathrm{G}\left(* \mathrm{~N}_{2} \rightarrow * \mathrm{NNH}\right) \mathrm{s}$ ranging from $0.30 \mathrm{eV}$ to $0.75 \mathrm{eV}$. Subsequently, the full reaction pathways were investigated. Here, we only considered commonly discussed distal and alternating reaction mechanisms, since $\mathrm{N}_{2}$ adsorptions are all in end-on configurations (Figure 4a). For the distal path, the first three $\mathrm{H}^{+} / \mathrm{e}^{-}$pairs attack the terminal $\mathrm{N}$ continuously, and another three $\mathrm{H}^{+} / \mathrm{e}^{-}$pairs attack the $\mathrm{N}$ atom connecting to the surface. In many previous studies, the N-N bond-breaking takes place at the third hydrogenation step $\left({ }^{*} \mathrm{NNH}_{2} \rightarrow{ }^{*} \mathrm{~N}+\mathrm{NH}_{3}\right){ }^{56,57}$ This phenomenon can also be observed in $\mathrm{W}$, Os, and $\mathrm{Ru} / \mathrm{Au}(111)$. While for $\mathrm{Mo} / \mathrm{Au}(111)$, the $\mathrm{N}-\mathrm{N}$ bond is cleaved at the fourth hydrogenation step $\left({ }^{*} \mathrm{NNH}_{3} \rightarrow * \mathrm{NH}+\mathrm{NH}_{3}\right)$. The $\mathrm{N}-\mathrm{N}$ bond-breaking is even at the fifth hydrogenation step $\left({ }^{*} \mathrm{NHNH}_{3} \rightarrow{ }^{*} \mathrm{NH}_{2}+\mathrm{NH}_{3}\right)$ on $\mathrm{Nb}$ and $\mathrm{Ta} / \mathrm{Au}(111)$, or the last hydrogenation step on $\mathrm{Ti}$ and $\mathrm{V} / \mathrm{Au}(111)$ (Figure 4b). Despite the first ammonia molecule desorbs at various steps, the PDSs are all the first hydrogenation steps $\left(* \mathrm{~N}_{2} \rightarrow * \mathrm{NNH}\right)($ Figure 4d).

In comparison, six $\mathrm{H}^{+} / \mathrm{e}^{-}$pairs attack two $\mathrm{N}$ atoms alternatively in the alternating mechanism. However, compared to distal mechanisms, the second hydrogenation step was hindered in alternating mechanism $(* \mathrm{NNH} \rightarrow * \mathrm{NHNH})$ for those SAAs, owing to the more positive free energy change (Table S5). For example, the $\Delta \mathrm{G}\left(* \mathrm{NNH} \rightarrow * \mathrm{NNH}_{2}\right)$ 
$(-0.72 \mathrm{eV})$ are much lower than the $\Delta \mathrm{G}\left({ }^{*} \mathrm{NNH} \rightarrow{ }^{*} \mathrm{NHNH}\right)(0.52 \mathrm{eV})$ on $\mathrm{W} / \mathrm{Au}(111)$.

Thus, the aforementioned eight SAAs show high activities with limiting potential $\left(\mathrm{U}_{\mathrm{L}}\right)$ ranging from $-0.30 \mathrm{~V}$ to $-0.75 \mathrm{~V}$ via distal mechanism(Figure 4c), which are better than $\mathrm{Ru}(0001)$ surface $\left(\mathrm{U}_{\mathrm{L}}=-0.98 \mathrm{~V}\right)$ with highest activity among bulk metals. ${ }^{16,58}$ Moreover, the activities of Mo and W/Au(111) are better than most single-atom catalysts (SACs) reported in experiments ${ }^{59-62}$ and theory simulations $56,57,63,64$ with limiting barriers of $0.30 \mathrm{eV}$.

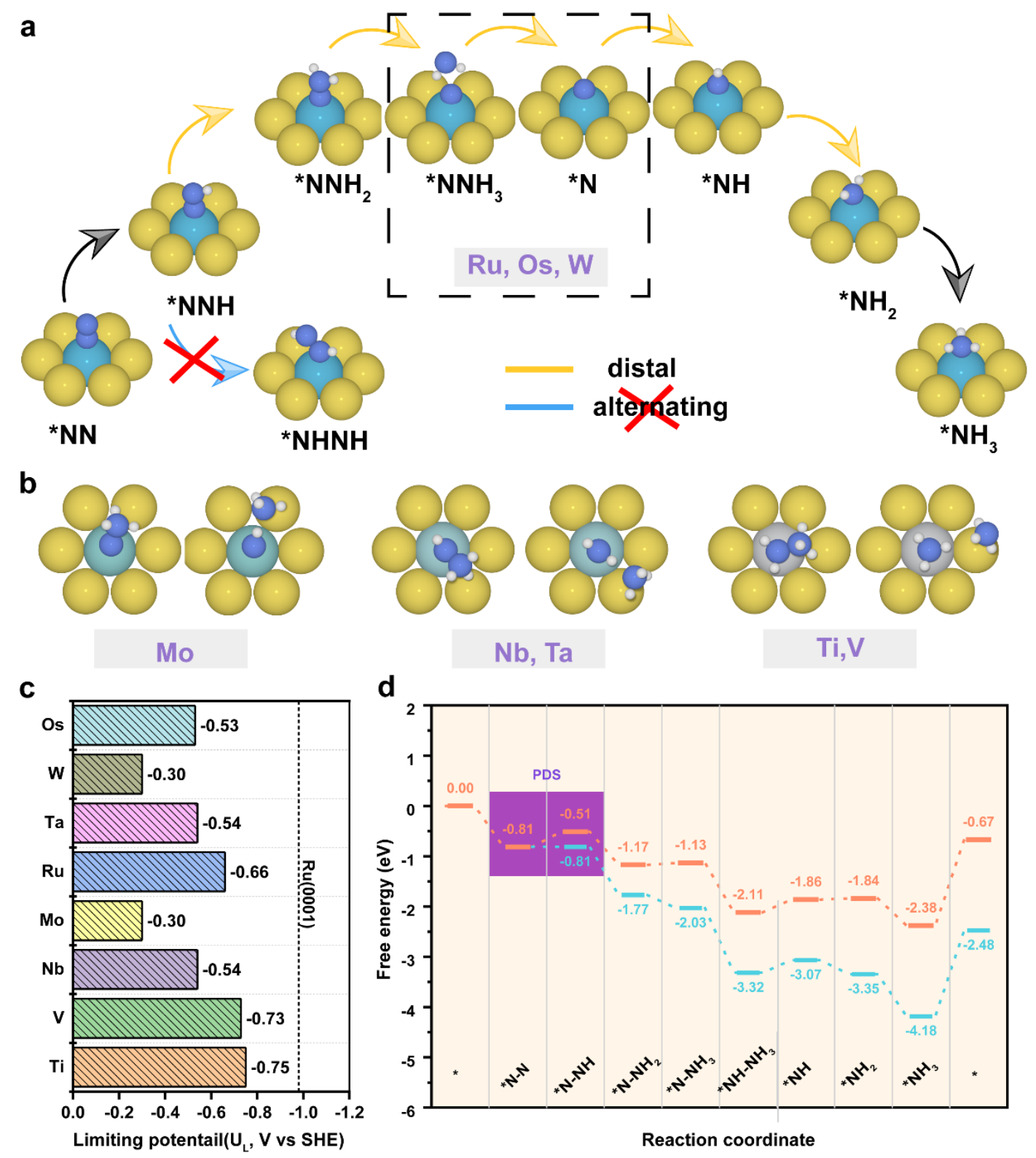

Figure 4. The reaction pathways of W/Au(111) through (a) distal mechanisms and (b) The N-N bond-breaking steps on typical SAAs.(c) The limiting potentials $\left(\mathrm{U}_{\mathrm{L}} \mathrm{s}\right)$ of 
SAAs and (d) The Free-energy diagram of $\mathrm{Mo} / \mathrm{Au}(111)$.

\subsection{The relationship between $\Delta G\left({ }^{*} \mathbf{N}_{2} \rightarrow * N N H\right)$ and intrinsic properties of doped}

\section{Metal.}

Based on previous analysis, the potential determining step of most promising eight candidates SAAs for NRR all are the first hydrogenation step $\left({ }^{*} \mathrm{~N}_{2} \rightarrow * \mathrm{NNH}\right)$. Thus, to further understand the relationship between $\Delta \mathrm{G}\left({ }^{*} \mathrm{~N}_{2} \rightarrow * \mathrm{NNH}\right)$ and electronic structures of SAAs, we analyzed the $\boldsymbol{d}$-band center of doped metal in each SAA, which is a commonly used descriptor in catalytic field. ${ }^{65}$ Figure 5(a) exhibits a volcano relationship between $\Delta \mathrm{G}\left({ }^{*} \mathrm{~N}_{2} \rightarrow{ }^{*} \mathrm{NNH}\right)$ and the $\boldsymbol{d}$-band center. The W- and Mo-doped systems are on the top, which possess the least positive $\Delta \mathrm{G}\left({ }^{*} \mathrm{~N}_{2} \longrightarrow * \mathrm{NNH}\right) \mathrm{s}$. The $d$-band center is still not an intrinsic descriptor. Inspired by previous studies, ${ }^{66-68}$ we purposed a new descriptor $\left(\frac{\mathbf{d}}{\sqrt{\mathbf{E}_{\mathbf{m}}}}\right)$ that only contains elemental physical parameters of dopant, namely electronegativity $\left(\mathrm{E}_{\mathrm{M}}\right)$ and the number of $d$-electron in valence orbital (d). From Figure 5(b), one can see that $\frac{\mathbf{d}}{\sqrt{\mathbf{E}_{\mathbf{m}}}}$ also shows a volcano relationship with $\Delta \mathrm{G}\left(* \mathrm{~N}_{2} \rightarrow * \mathrm{NNH}\right)$. Thus we suggest that one can simply predict the performance based on this intrinsic descriptor. For example, we predicted that Mo and $\mathrm{W} / \mathrm{Ag}(111)$ may also exhibit high activity with low energy barriers of $\Delta \mathrm{G}\left({ }^{*} \mathrm{~N}_{2} \rightarrow * \mathrm{NNH}\right)$ owing to similar electronic structures of $\mathrm{Ag}$ and $\mathrm{Au}$. The further simulation shows that $\Delta \mathrm{G}\left({ }^{*} \mathrm{~N}_{2} \rightarrow{ }^{*} \mathrm{NNH}\right)$ for Mo and $\mathrm{W} / \mathrm{Ag}(111)$ are 0.19 and $0.09 \mathrm{eV}$, respectively. The distal mechanism is preferred, similar to the Au-based system. Whereas the PDSs are the third hydrogenation step $\left(* \mathrm{NNH}_{2} \rightarrow * \mathrm{NNH}_{3}\right)$ with free energy changes of 0.46 and $0.47 \mathrm{eV}$ for Mo and W/Ag(111), respectively. Herein these Ag-based alloys are also promising for NRR. These findings indicate that building a simple intrinsic descriptor can effectively design catalysts to reduce large computational resources. 

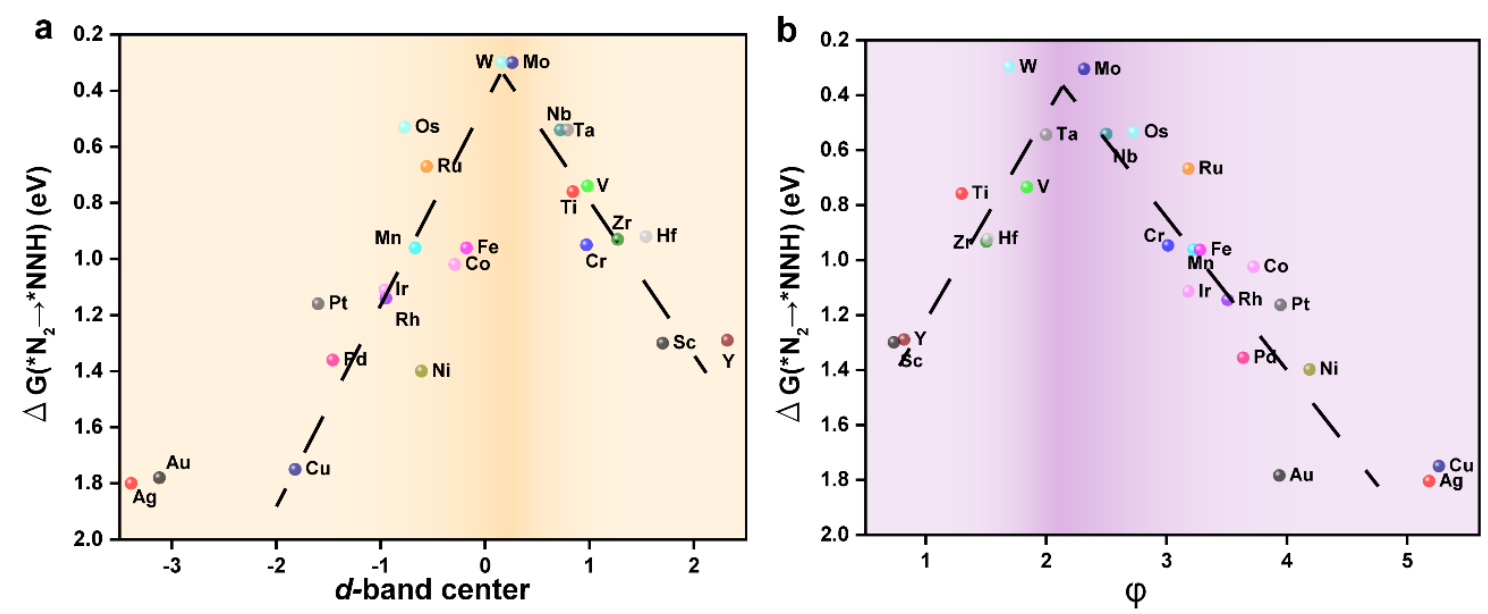

Figure 5. The volcano relationships between $\Delta \mathrm{G}\left({ }^{*} \mathrm{~N}_{2} \rightarrow * \mathrm{NNH}\right)$ and (a) d-band center and (b) $\varphi$ that equals to $\frac{\mathbf{d}}{\sqrt{\mathbf{E}_{\mathbf{m}}}}$.

Moreover, we applied the Random Forest Algorithm (RFA) in Scikit-learn to analyze the relationship between properties of dopant metal and $\Delta \mathrm{G}\left({ }^{*} \mathrm{~N}_{2} \longrightarrow * \mathrm{NNH}\right){ }^{69}$ Inspired by previous research, ${ }^{70-72}$ five parameters of doped metal were identified as the input data, including the number of $d$-electron, radius, the group number, electronegativity, and electron affinity. As shown in Figure 6a, the RFA model performs well with a training score of 0.96 and a testing score of 0.90 . The result shows that the group number and d-electron are the two most important features (Figure 6b). They decide the electron distribution in the outer shell of dopant, which directly affects the interactions ( $\sigma$-donation and $\pi$-backdonation) between dopant and adsorbate. We suggest that the machine-learning technology can be used to accelerate the discovery of efficient SAA for NRR. 

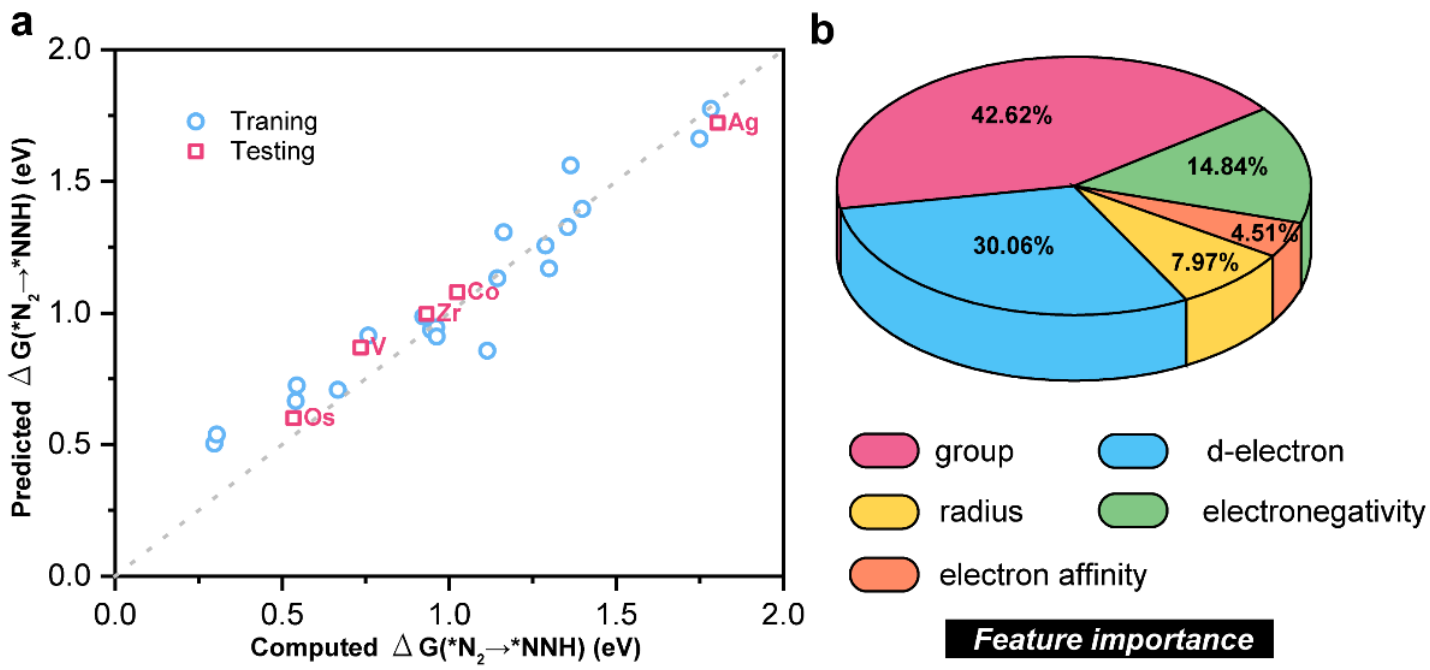

Feature importance

Figure 6. (a) Comparison between DFT and predicted $\Delta \mathrm{G}\left({ }^{*} \mathrm{~N}_{2} \rightarrow * N N H\right)$. (b) Importance of features from the Random Forest model for $\Delta \mathrm{G}\left(* \mathrm{~N}_{2} \rightarrow * \mathrm{NNH}\right)$.

\subsection{The potential application of SAAs on NRR.}

a
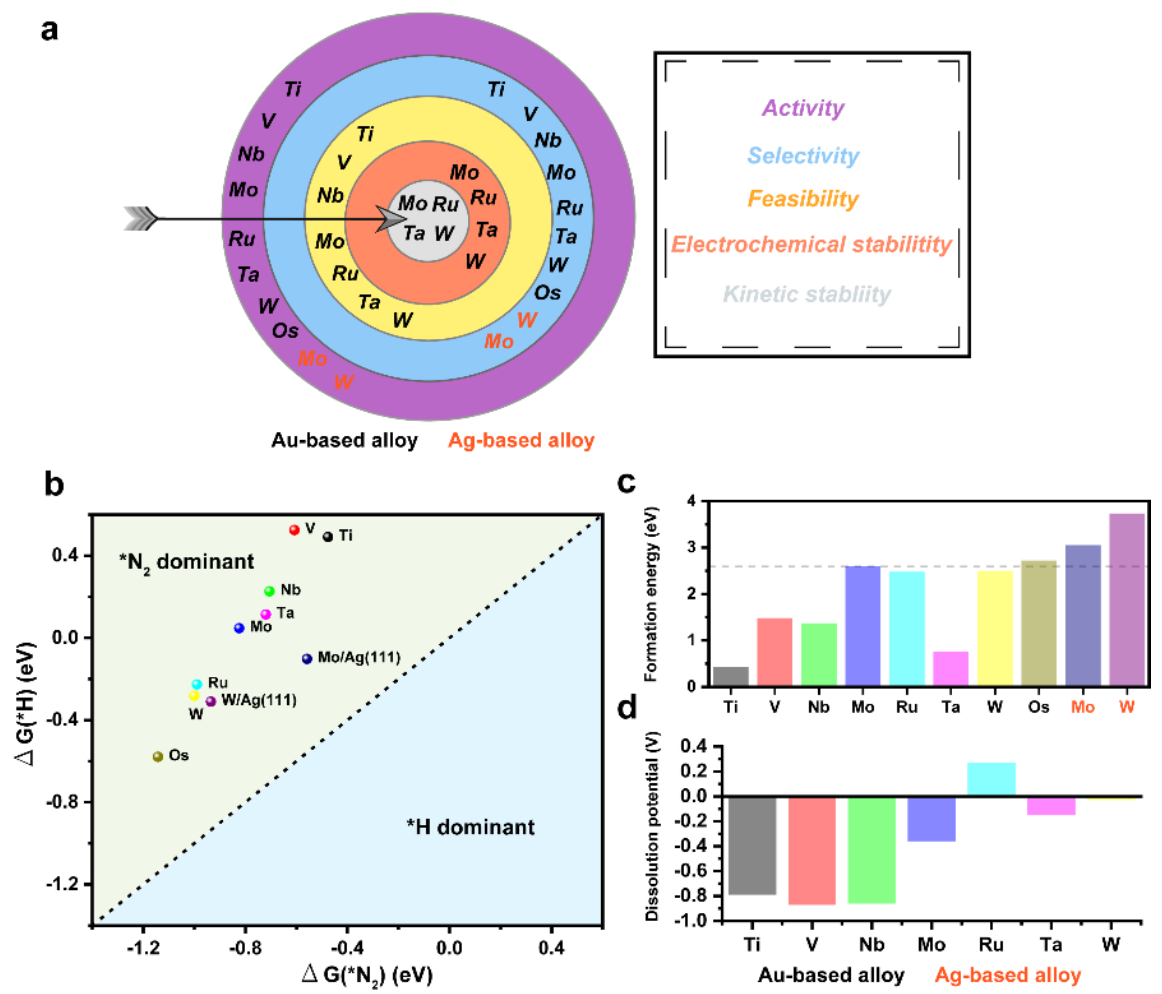

Figure 7. (a) The illustration of the evaluating process. (b) The calculated $\Delta G\left({ }^{*} N_{2}\right)$ and $\Delta \mathrm{G}\left({ }^{*} \mathrm{H}\right)$. The left upper corner is the ${ }^{*} \mathrm{~N}_{2}$ dominant region where $\Delta \mathrm{G}\left({ }^{*} \mathrm{H}\right)>\Delta \mathrm{G}\left({ }^{*} \mathrm{~N}_{2}\right)$. 
(c) The formation energies of SAAs. (d) The dissolution potentials of SAAs.

Selectivity. Besides activity, an ideal NRR electrocatalyst should be able to suppress the hydrogenation evolution reduction (HER) to achieve high faradaic efficiency. ${ }^{73-75}$ To evaluate the selectivity of the eight $\mathrm{M} / \mathrm{Au}(111)$ and two $\mathrm{M} / \mathrm{Ag}(111)$ SAAs, we compared $\Delta \mathrm{G}\left({ }^{*} \mathrm{H}\right)$ and $\Delta \mathrm{G}\left({ }^{*} \mathrm{~N}_{2}\right)$. As shown in Figure $7 \mathbf{b}$, one can see that these eight SAAs possess positive values of $\left(\Delta \mathrm{G}\left({ }^{*} \mathrm{H}\right)-\Delta \mathrm{G}\left({ }^{*} \mathrm{~N}_{2}\right)\right)$, indicating that these surfaces tend to capture nitrogen rather than hydrogen and then lead to the expected NRR selectivity. ${ }^{60,64}$

Feasibility. Moreover, an applicable electrocatalyst should be facile in experiment. To investigate the synthetic accessibility of selected candidates, we calculated their formation energies $\left(\mathrm{E}_{\text {forms }}\right)($ Figure $7 \mathbf{c}) . \mathrm{Mo} / \mathrm{Au}(111)$ was taken as a reference since it has been synthesized. ${ }^{76}$ Except for $\mathrm{Os} / \mathrm{Au}(111), \mathrm{Mo} / \mathrm{Ag}(111)$, and W/Ag(111), other five Au-based SAAs show less positive $E_{\text {form }}$ values than that of $\mathrm{Mo} / \mathrm{Au}(111)(2.59 \mathrm{eV})$ (Figure 7c), implying that these materials are more readily synthesized in experiment.

Electrochemical stability. To evaluate the electrochemical stability in electrolyte, the dissolution potential ( $\mathrm{U}_{\text {diss }}$ ) of the seven $\mathrm{M} / \mathrm{Au}(111)$ SAAs ( $\mathrm{M}=\mathrm{Ti}, \mathrm{V}, \mathrm{Nb}, \mathrm{Mo}, \mathrm{Ru}$, Ta, and $\mathrm{W}$ ) were calculated to compare with that of prepared $\mathrm{Mo} / \mathrm{Au}(111)$, which exhibits long-term stability for effective $\mathrm{CO}_{2}$ electrochemical reduction. ${ }^{13,52}$ From Figure 7d, $\mathrm{Ru}, \mathrm{Ta}$, and $\mathrm{W} / \mathrm{Au}(111)$ systems possess more positive $U_{\text {diss }}$ than $\mathrm{Mo} / \mathrm{Au}(111)$, corresponding to their long-term stability in electrochemical reductive environment, namely the high electrochemical stability. ${ }^{76}$

Kinetic stability. Now Mo, $\mathrm{Ru}, \mathrm{Ta}$, and W/Au(111) are picked out as candidates through the evaluation of feasibility and electrochemical stability. Then the aggregation of a single atom on the substrate is checked based on the difference between binding energy $\left(E_{b}\right)$ and cohesive energy $\left(E_{c}\right)$ of the doped transition metal. The $\left(E_{b}-E_{c}\right)$ values of Ta, Mo, W, and Ru are $1.34,-0.49,-0.40$, and $-0.38 \mathrm{eV}$, respectively. The positive $\left(E_{b}-E_{c}\right)$ value of Ta-containing system is related to highly thermal stability. Beyond thermal stability, single-atom system can still be kinetically stable, such as the 
synthesized $\mathrm{Mo} / \mathrm{Au}(111) .^{20,77,78}$ In comparison, $\mathrm{Ru}$ - and $\mathrm{W}$-containing systems possess more positive values of $\mathrm{E}_{\mathrm{b}}(7.40$ and $8.46 \mathrm{eV})$ than that of $\mathrm{Mo} / \mathrm{Au}(111)(7.08 \mathrm{eV})$, hence they can be kinetically stable in preparation and electrocatalysis.

After evaluating selectivity, feasibility, and stability, the Mo, Ru, Ta, and W/Au(111) SAAs are finally screened out as the potential electrocatalysts for NRR (Figure 7a).

\section{Conclusion}

In summary, a series of SAAs were investigated as candidates for NRR by using DFT calculation. Simulation results show that the alloying strategy effectively enhances the strength of $\mathrm{N}_{2}$ adsorption and thus reduces the free energy barriers of the first hydrogenation step. Compared to $\mathrm{Au}(111)$ surface, eight $\mathrm{M} / \mathrm{Au}(111)$ systems $(\mathrm{M}=\mathrm{Ti}, \mathrm{V}$, $\mathrm{Nb}, \mathrm{Mo}, \mathrm{Ru}, \mathrm{Ta}, \mathrm{W}$, and $\mathrm{Os})$ reduce the barrier of $\mathrm{PDS}\left(\Delta \mathrm{G}\left({ }^{*} \mathrm{~N}_{2} \rightarrow * \mathrm{NNH}\right)\right)$ over $1.0 \mathrm{eV}$, corresponding to high activity with limiting potential ranging from $-0.30 \mathrm{~V}$ to $-0.75 \mathrm{~V}$. Three descriptors were proposed to describe, $\Delta \mathrm{G}\left({ }^{*} \mathrm{~N}_{2} \rightarrow * \mathrm{NNH}\right)$, including $\Delta \mathrm{G}\left({ }^{*} \mathrm{NNH}\right)$, $d$-band center, and $\frac{\mathbf{d}}{\sqrt{\mathbf{E}_{\mathbf{m}}}}$. Since the new descriptor is only related to the intrinsic properties of doped elements, we predict that Mo and W/Ag(111) possess high activity as well. Random Forest algorithm in machine learning was used to investigate the relationship between intrinsic properties of doped metal and $\Delta \mathrm{G}\left({ }^{*} \mathrm{~N}_{2} \rightarrow{ }^{*} \mathrm{NNH}\right)$. Finally, the selectivity over HER, feasibility, electrochemical, and kinetic stability were computed to evaluate the potential application of SAAs. Four SAAs (Mo, W, Ru, and $\mathrm{Ta} / \mathrm{Au}(111))$ were screened out as promising electrocatalysts for NRR. We hope our work can inspire both theoretical and experimental investigations on SAAs for NRR. 


\section{Reference}

1 G. Qing, R. Ghazfar, S. T. Jackowski, F. Habibzadeh, M. M. Ashtiani, C.-P. Chen, M. R. Smith and T. W. Hamann, Chem. Rev., 2020, 120, 5437-5516.

2 J. Li, S. Chen, F. Quan, G. Zhan, F. Jia, Z. Ai and L. Zhang, Chem, 2020, 6, 885-901.

3 V. Kyriakou, I. Garagounis, A. Vourros, E. Vasileiou and M. Stoukides, Joule, 2020, 4, 142-158.

4 W. Guo, K. Zhang, Z. Liang, R. Zou and Q. Xu, Chem. Soc. Rev., 2019, 48, 5658-5716.

5 S. L. Foster, S. I. P. Bakovic, R. D. Duda, S. Maheshwari, R. D. Milton, S. D. Minteer, M. J. Janik, J. N. Renner and L. F. Greenlee, Nat. Catal., 2018, 1, 490-500.

6 B. H. R. Suryanto, H.-L. Du, D. Wang, J. Chen, A. N. Simonov and D. R. MacFarlane, Nat. Catal., 2019, 2, 290-296.

7 V. Kordali, G. Kyriacou and C. Lambrou, Chem. Commun., 2000, 1673-1674.

8 H. K. Lee, C. S. L. Koh, Y. H. Lee, C. Liu, I. Y. Phang, X. Han, C.-K. Tsung and X. Y. Ling, Sci. $A d v$, 2018, 4, eaar3208.

9 Y.-J. Mao, L. Wei, X.-S. Zhao, Y.-S. Wei, J.-W. Li, T. Sheng, F.-C. Zhu, N. Tian, Z.-Y. Zhou and S.-G. Sun, Chem. Commun., 2019, 55, 9335-9338.

10 J. Li, G. Zhan, J. Yang, F. Quan, C. Mao, Y. Liu, B. Wang, F. Lei, L. Li, A. W. M. Chan, L. Xu, Y. Shi, Y. Du, W. Hao, P. K. Wong, J. Wang, S.-X. Dou, L. Zhang and J. C. Yu, J. Am. Chem. Soc., 2020, 142, 7036-7046.

11 H.-J. Yin, J.-H. Zhou and Y.-W. Zhang, Inorg. Chem. Front., 2019, 6, 2582-2618.

12 Z. W. Seh, J. Kibsgaard, C. F. Dickens, I. Chorkendorff, J. K. Nørskov and T. F. Jaramillo, Science, 2017, 355, eaad4998.

13 M.-A. Légaré, G. Bélanger-Chabot, R. D. Dewhurst, E. Welz, I. Krummenacher, B. Engels and H. Braunschweig, Science, 2018, 359, 896-900.

14 C. Ling, Y. Ouyang, Q. Li, X. Bai, X. Mao, A. Du and J. Wang, Small Methods, 2019, 3, 1800376. 15 J. H. Montoya, C. Tsai, A. Vojvodic and J. K. Nørskov, ChemSusChem, 2015, 8, 2180-2186.

16 E. Skúlason, T. Bligaard, S. Gudmundsdóttir, F. Studt, J. Rossmeisl, F. Abild-Pedersen, T. Vegge, H. Jónsson and J. K. Nørskov, Phys Chem Chem Phys, 2012, 14, 1235-1245.

17 B. Qiao, A. Wang, X. Yang, L. F. Allard, Z. Jiang, Y. Cui, J. Liu, J. Li and T. Zhang, Nat. Chem., 2011, 3, 634-641.

18 Z. Li, S. Ji, Y. Liu, X. Cao, S. Tian, Y. Chen, Z. Niu and Y. Li, Chem. Rev., 2020, 120, 623-682. 19 W. Zang, Z. Kou, S. J. Pennycook and J. Wang, Adv Energy Mater, 2020, 18.

20 Y. Wang, J. Mao, X. Meng, L. Yu, D. Deng and X. Bao, Chem. Rev., 2019, 119, 1806-1854.

21 Z. Zhang, Y. Zhu, H. Asakura, B. Zhang, J. Zhang, M. Zhou, Y. Han, T. Tanaka, A. Wang, T. Zhang and N. Yan, Nat. Commun., 2017, 8, 16100.

22 M. Moses-DeBusk, M. Yoon, L. F. Allard, D. R. Mullins, Z. Wu, X. Yang, G. Veith, G. M. Stocks and C. K. Narula, J. Am. Chem. Soc., 2013, 135, 12634-12645.

23 F. Maurer, J. Jelic, J. Wang, A. Gänzler, P. Dolcet, C. Wöll, Y. Wang, F. Studt, M. Casapu and J.D. Grunwaldt, Nat. Catal., 2020, 1-10.

24 L. Nie, D. Mei, H. Xiong, B. Peng, Z. Ren, X. I. P. Hernandez, A. DeLaRiva, M. Wang, M. H. Engelhard, L. Kovarik, A. K. Datye and Y. Wang, Science, 2017, 358, 1419-1423.

25 W. Qu, X. Liu, J. Chen, Y. Dong, X. Tang and Y. Chen, Nat. Commun., 2020, 11, 1532.

26 J. Lin, A. Wang, B. Qiao, X. Liu, X. Yang, X. Wang, J. Liang, J. Li, J. Liu and T. Zhang, J. Am. Chem. Soc., 2013, 135, 15314-15317.

27 H. Fei, J. Dong, Y. Feng, C. S. Allen, C. Wan, B. Volosskiy, M. Li, Z. Zhao, Y. Wang, H. Sun, P. 
An, W. Chen, Z. Guo, C. Lee, D. Chen, I. Shakir, M. Liu, T. Hu, Y. Li, A. I. Kirkland, X. Duan and Y. Huang, Nat. Catal., 2018, 1, 63-72.

28 Y. Peng, B. Lu and S. Chen, Adv. Mater., 2018, 30, 1801995.

29 P. Vancsó, Z. I. Popov, J. Pető, T. Ollár, G. Dobrik, J. S. Pap, C. Hwang, P. B. Sorokin and L. Tapasztó, ACS Energy Lett., 2019, 4, 1947-1953.

30 Y. Shi, W.-M. Huang, J. Li, Y. Zhou, Z.-Q. Li, Y.-C. Yin and X.-H. Xia, Nat. Commun., 2020, 11, 4558.

31 G. Liu, A. W. Robertson, M. M.-J. Li, W. C. H. Kuo, M. T. Darby, M. H. Muhieddine, Y.-C. Lin, K. Suenaga, M. Stamatakis, J. H. Warner and S. C. E. Tsang, Nat. Chem., 2017, 9, 810-816.

32 J. Zhang, Y. Zhao, X. Guo, C. Chen, C.-L. Dong, R.-S. Liu, C.-P. Han, Y. Li, Y. Gogotsi and G. Wang, Nat. Catal., 2018, 1, 985-992.

33 D. Zhao, Z. Chen, W. Yang, S. Liu, X. Zhang, Y. Yu, W.-C. Cheong, L. Zheng, F. Ren, G. Ying,

X. Cao, D. Wang, Q. Peng, G. Wang and C. Chen, J. Am. Chem. Soc., 2019, 141, 4086-4093.

34 R. T. Hannagan, G. Giannakakis, M. Flytzani-Stephanopoulos and E. C. H. Sykes, Chem. Rev, 2020, acs.chemrev.0c00078.

35 G. Kyriakou, M. B. Boucher, A. D. Jewell, E. A. Lewis, T. J. Lawton, A. E. Baber, H. L. Tierney, M. Flytzani-Stephanopoulos and E. C. H. Sykes, Science, 2012, 335, 1209-1212.

36 G. Giannakakis, M. Flytzani-Stephanopoulos and E. C. H. Sykes, Acc. Chem. Res., 2019, 52, 237-247.

37 R. Long, Y. Li, Y. Liu, S. Chen, X. Zheng, C. Gao, C. He, N. Chen, Z. Qi, L. Song, J. Jiang, J. Zhu and Y. Xiong, J. Am. Chem. Soc., 2017, 139, 4486-4492.

38 J. Li, A. Xu, F. Li, Z. Wang, C. Zou, C. M. Gabardo, Y. Wang, A. Ozden, Y. Xu, D.-H. Nam, Y. Lum, J. Wicks, B. Chen, Z. Wang, J. Chen, Y. Wen, T. Zhuang, M. Luo, X. Du, T.-K. Sham, B. Zhang, E. H. Sargent and D. Sinton, Nat. Commun., 2020, 11, 3685.

39 J. Mao, C.-T. He, J. Pei, Y. Liu, J. Li, W. Chen, D. He, D. Wang and Y. Li, Nano Lett., 2020, 20, 3442-3448.

40 J. M. P. Martirez and E. A. Carter, ACS Nano, 2016, 10, 2940-2949.

41 J. M. P. Martirez and E. A. Carter, $S c i . A d v$., 2017, 3, eaao4710.

42 Y. Wang, L. Cao, N. J. Libretto, X. Li, C. Li, Y. Wan, C. He, J. Lee, J. Gregg, H. Zong, D. Su, J.

T. Miller, T. Mueller and C. Wang, J. Am. Chem. Soc., , DOI:10.1021/jacs.9b05766.

43 G. Kresse and J. Furthmüller, Phys. Rev. B, 1996, 54, 11169-11186.

44 J. P. Perdew, K. Burke and M. Ernzerhof, Phys. Rev. Lett., 1996, 77, 3865-3868.

45 G. Kresse and D. Joubert, Phys. Rev. B, 1999, 59, 1758-1775.

46 S. Grimme, J. Comput. Chem., 2006, 27, 1787-1799.

47 H. J. Monkhorst and J. D. Pack, Phys. Rev. B, 1976, 13, 5188-5192.

48 [1908.08269] VASPKIT: A Pre- and Post-Processing Program for VASP code, https://arxiv.org/abs/1908.08269, (accessed December 11, 2019).

49 The atomic simulation environment - a Python library for working with atoms - IOPscience, https://iopscience.iop.org/article/10.1088/1361-648X/aa680e, (accessed February 20, 2020).

50J. K. Nørskov, J. Rossmeisl, A. Logadottir, L. Lindqvist, J. R. Kitchin, T. Bligaard and H. Jónsson, J. Phys. Chem. B, 2004, 108, 17886-17892.

51 K. Mathew, R. Sundararaman, K. Letchworth-Weaver, T. A. Arias and R. G. Hennig, J. Chem. Phys., 2014, 140, 084106.

52 X. Guo, J. Gu, S. Lin, S. Zhang, Z. Chen and S. Huang, J. Am. Chem. Soc., 2020, 142, 5709- 
5721.

53 X. Cui, C. Tang and Q. Zhang, Adv. Energy Mater, 2018, 8, 1800369.

54 M. Yu and D. R. Trinkle, J. Chem. Phys., 2011, 134, 064111.

55 S. Tang, T. Liu, Q. Dang, X. Zhou, X. Li, T. Yang, Y. Luo, E. Sharman and J. Jiang, J. Phys. Chem. Lett., 2020, 11, 5051-5058.

56 L. Li, X. Wang, H. Guo, G. Yao, H. Yu, Z. Tian, B. Li and L. Chen, Small Methods, 2019, 3, 1900337.

57 L. Cai, N. Zhang, B. Qiu and Y. Chai, ACS Appl. Mater. Interfaces, 2020, 12, 20448-20455.

58 X. Guo, S. Lin, J. Gu, S. Zhang, Z. Chen and S. Huang, Adv. Funct. Mater, n/a, 2008056.

59 Y. Ma, T. Yang, H. Zou, W. Zang, Z. Kou, L. Mao, Y. Feng, L. Shen, S. J. Pennycook, L. Duan,

X. Li and J. Wang, Adv. Mater., 2020, 2002177.

60 H. Tao, C. Choi, L.-X. Ding, Z. Jiang, Z. Han, M. Jia, Q. Fan, Y. Gao, H. Wang, A. W. Robertson,

S. Hong, Y. Jung, S. Liu and Z. Sun, Chem, 2019, 5, 204-214.

61 Y. Chen, R. Guo, X. Peng, X. Wang, X. Liu, J. Ren, J. He, L. Zhuo, J. Sun, Y. Liu, Y. Wu and J.

Luo, ACS Nano, 2020, 14, 6938-6946.

62 Z. Geng, Y. Liu, X. Kong, P. Li, K. Li, Z. Liu, J. Du, M. Shu, R. Si and J. Zeng, Adv. Mater, 2018, 30, 1803498.

63 S. Wang, W. Wei, X. Lv, B. Huang and Y. Dai, J. Mater. Chem. A, 2020, 10.1039.C9TA10935H.

64 C. Choi, S. Back, N.-Y. Kim, J. Lim, Y.-H. Kim and Y. Jung, ACS Catal., 2018, 8, 7517-7525.

65 E. Santos and W. Schmickler, ChemPhysChem, 2006, 7, 2282-2285.

66 H. Guo, L. Li, X. Wang, G. Yao, H. Yu, Z. Tian, B. Li and L. Chen, ACS Appl. Mater. Interfaces, 2019, 11, 36506-36514.

67 W. Gao, Y. Chen, B. Li, S.-P. Liu, X. Liu and Q. Jiang, Nat. Commun., 2020, 11, 1196.

68 H. Xu, D. Cheng, D. Cao and X. C. Zeng, Nat. Catal., 2018, 1, 339-348.

69 F. Pedregosa, G. Varoquaux, A. Gramfort, V. Michel, B. Thirion, O. Grisel, M. Blondel, P. Prettenhofer, R. Weiss, V. Dubourg, J. Vanderplas, A. Passos and D. Cournapeau, J. Mach. Learn. Res., 2011, 12, 2825--2830.

70 X. Guo, S. Lin, J. Gu, S. Zhang, Z. Chen and S. Huang, ACS Catal., 2019, 11042-11054.

71 L. Wu, T. Guo and T. Li, J. Mater. Chem. A, , DOI:10/ghc8d3.

72 H. Yuan, Z. Li, X. C. Zeng and J. Yang, J. Phys. Chem. Lett., 2020, 11, 3481-3487.

73 A. R. Singh, B. A. Rohr, M. J. Statt, J. A. Schwalbe, M. Cargnello and J. K. Nørskov, ACS Catal., 2019, 9, 8316-8324.

74 S. D. Minteer, P. Christopher and S. Linic, ACS Energy Lett., 2019, 4, 163-166.

75 A. R. Singh, B. A. Rohr, J. A. Schwalbe, M. Cargnello, K. Chan, T. F. Jaramillo, I. Chorkendorff and J. K. Nørskov, ACS Catal., 2017, 7, 706-709.

76 K. Sun, Y. Ji, Y. Liu and Z. Wang, J. Mater. Chem. A, 2020, 8, 12291-12295.

77 X.-F. Yang, A. Wang, B. Qiao, J. Li, J. Liu and T. Zhang, Acc. Chem. Res., 2013, 46, 1740-1748. 78 J. Liu, ACS Catal., 2017, 7, 34-59. 
TOC

Electrochemical Nitrogen Reduction Reaction

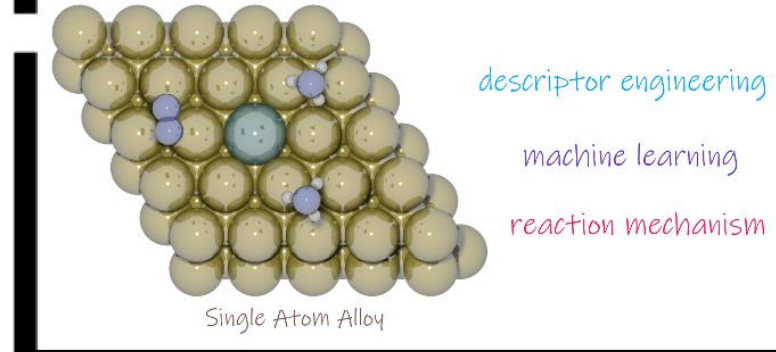

High-Throughput Screening

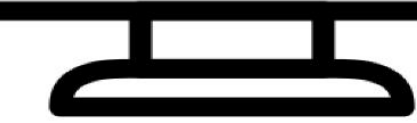

